\title{
The Exploration of a Phased Comprehensive Examination Method in College Physics Experiments
}

\author{
Xinshun Wang, Benyang Wang, Wenge Qu, Weiyan Jiao, Chengfeng Li, Guanghua Fan, \\ Yi Liu, Shukun Zhao \\ School of Science, Harbin Institute of Technology at Weihai, Shandong, Weihai, China \\ Email: wangxinshun@hit.edu.cn
}

How to cite this paper: Wang, X.S., Wang, B.Y., Qu, W.G., Jiao, W.Y., Li, C.F., Fan, G.H., Liu, Y. and Zhao, S.K. (2019) The Exploration of a Phased Comprehensive Examination Method in College Physics Experiments. Open Journal of Social Sciences, 7, 161-170.

https://doi.org/10.4236/jss.2019.73013

Received: January 15, 2019

Accepted: March 10, 2019

Published: March 13, 2019

\begin{abstract}
Examination method is like a baton, and its reform can greatly improve the teaching effect of college physics experiment course and change the students' learning styles. Based on the current experimental teaching mode in our school, a new phased comprehensive examination method and the corresponding evaluation standard in college physics experiments were discussed in detail. This examination method is very appropriate to the hierarchical phased teaching model and course system. It can guide students to attach importance to experimental process, actively practice, continuous innovation and is beneficial to fully develop the potential of students, cultivate their active exploration spirit, scientific thinking ability, innovation ability and innovation consciousness, which truly achieve quality education.
\end{abstract}

\section{Keywords}

College Physics Experiment Course System, Teaching Model of " $2+1$ "

In-Class and Extracurricular Integration, Phased Comprehensive

Examination Method, Evaluation Standard, Innovation Ability Cultivation

\section{Introduction}

"Basic requirements for the teaching of college physics experiments in university of science and technology" [1] clearly points out that the college physics experiment is an important practical course in which students are systematically and scientifically trained in experimental techniques and methods, students' scientific thinking and innovative consciousness have been developed, and their scientific experimental ability, literacy, and innovation ability have been improved. 
Compared with other practical courses, this course plays an irreplaceable role in cultivating students' rigorous academic attitude, active innovation consciousness, theoretical connection practice and comprehensive application ability adapting to the development of science and technology. Therefore, most colleges and universities attach great importance on the teaching quality of physics experiment course, and adopt various methods to improve students' initiative, enthusiasm and consciousness and stimulate students' interest in learning [2] [3] [4] [5] [6]. With the continuous advancement of curriculum reform, a hierarchical, phased university physics experiment teaching model with different goals has been popularized and applied in many colleges and universities [7] [8] [9] [10]. The new curriculum system of college physics experiment (basic physics experiments, comprehensive design experiments, independent innovation experiments, research experiments) from basic to frontier, from receiving knowledge to cultivating ability has also been formed. The reform of teaching mode and curriculum system has made some students stand out and their enthusiasm and initiative in learning have been improved obviously. However, in order to benefit most students and achieve the goal of "Basic requirements for the teaching of college physics experiments in university of science and technology", the traditional assessment methods can no longer meet the current teaching system. There is an urgent need for a new assessment system to comply with the new teaching reform. The assessment system must be adapted to the teaching model and curriculum system, otherwise, the effect of teaching reform will be greatly compromised.

At present, many colleges and universities have made an attempt to reform college physics experiment examination method, which has partly changed the traditional examination method (the traditional examination method: ordinary score of oral question + experimental report score + final theoretical written exams or operation test) [11] [12] [13]. In view of teaching characteristics and teaching objectives for different levels of students, Beijing University of Technology has adopted a variety of examination methods [14]. The Logistics Engineering College of the Chinese people's Liberation Army has adopted a phased examination method [15]. National University of Defence Technology evaluates the course score in the form of traditional examination and small papers [16], and so on. The exam is a baton, what kind of assessment method is there, and what kind of learning style the students will have. The reform of examination method has greatly improved the teaching effect of college physics experiment course and changed the students' learning style. Our university physics experiment center focuses on people-oriented, promoting students' development and improving students' interest in learning. The experimental teaching philosophy is based on cultivating students' practical ability, scientific literacy and innovative ability. In line with education humanization and individuation, the reform of teaching mode, curriculum system and examination method is carried out. Taking the current experimental teaching model of our university as an example, this paper discusses the comprehensive course assessment method. 


\section{The Curriculum System and Teaching Mode of College Physics Experiment}

\subsection{College Physics Experiment Course System}

The physics experiment course of Harbin institute of technology at Weihai is offered to more than 2000 undergraduate students of science and engineering. The experiment is divided into two semesters, one in the first semester of second grade and the other in the second one. At present, there are 23 basic physical experiments, 6 comprehensive physical experiments and 3 designed physical experiments (including Do It Yourself experiments) in the University Physics experiment Center. In addition, five innovative research experimental courses have been set up independently, including optical combination, holographic optical information processing, laser interferometry technology and application, laser induced breakdown spectroscopy application, and nuclear magnetic resonance technology and application innovative research experiment course. Now, our experimental center has established a multi-level modular experimental teaching course system with the goal of capacity training, from basic experiments to comprehensive experiments to design experiments and innovative research experiments.

\subsection{Teaching Mode of College Physics Experiment}

The physics experiment center of Harbin institute of Technology at Weihai has implemented a new teaching model of " $2+1$ " in-class and extracurricular integration. The " $2+1$ " teaching mode consists of three parts: experimental operation in class, experimental discussion, and extracurricular independent expansion experiment. During experimental discussion in class, the students are the main ones, the teachers are the secondary ones. Firstly, teacher and students discuss the problems or mistakes in experiment operation or experiment report, analyze the factors that affect the accuracy of the experiment, put forward some measures to improve the accuracy of the experiment, and discuss how to solve and correct the problems or mistakes in the experiment operation or the report of the experiment and how to solve and correct the problems; secondly, students share their experience of the experiment and the results of online research after class, such as the classical physical ideas, principles, or the application of classical physical measurement methods in actual industrial and agricultural production or in daily life, and so on; thirdly, students discuss the main instrument can do what experiments else, what aspects can be applied, and after adding some equipment whether the experimental equipment can do some extended experiments or scientific and technological innovation, and so on. The main purpose of class discussion is to broaden students' horizons and develop students' divergent thinking ability. Extracurricular independent expansion experiment is closely connected with in-class experiment, which is an extension of the in-class experiment. According to the discussion in class, students can draw up their own experimental topic, design the experiment scheme, build the experimental 
platform, conduct an experimental research, and write out the research report by themselves.

The three parts of the " $2+1$ " teaching model are an indivisible whole. The experiment operation in class is the foundation, the experimental discussion in the class has played a role in summing up and improving the experiment operation in class, which connect the experiment operation in class with the extracurricular independent expansion experiment, and the extracurricular independent expansion experiment reaches the peak, in which students' interest in learning and innovation consciousness have been stimulated, their field of vision has been broadened, their spirit of exploration has been cultivated, and their practical and innovative ability have been strengthened. The three parts are promoted from low to high, so that students will not have a sense of hardship, and it is easy to realize the migration of learning. In the unconsciously, the students' practical ability and innovative ability have been improved.

\section{Phased Comprehensive Examination Method in College Physics Experiments}

\subsection{The Total Score Composition of College Physics Experiments}

The total score of the college physics experiments consists of three parts: class discussion (10\%), experiment in class (80\%), and extracurricular expansion experiment $(10 \%)$. This examination method matches our curriculum and teaching model very well.

\subsection{The Score of Class Discussion}

The course discussion is set in the first 20 minutes of each experiment class. The discussion content has been described in the 1.2 (The college physics experiment teaching mode), and will not be repeated here. The score of the course discussion are calculated based on the total number of times a student has spoken in one semester. The score of the student who is the most frequent participation in the class is 10 points.

\subsection{The Phased Comprehensive Examination of Experiment in Class}

Experiments in class are conducted in stages throughout the semester. The basic experiment was placed in the first half of the semester, and the comprehensive and design experiments were placed in the second half of the semester. After the basic experiments are completed, the class will be suspended for one week. All the score of basic experiments will be judged by teachers in this week. If the average score is unqualified, the next stage of comprehensive and design experiments will not be carried out. The score of this course in this semester will be unsuccessful and this course needs to be relearned in the next school year. Only those who have passed the average score of the basic experiments can carry out the next phase of comprehensive and design experiments. 
The total score of the experiments in class is $80 \%$ of the sum of the score of ten individual experiments in class in one semester. The score of a single experiment in class is divided into four parts: experimental preparation (20\%), experimental operation (20\%), experimental literacy (20\%), and experimental report (40\%).

1) Experimental preparation:

In order to cultivate students' ability of independent learning, independent experiment, independent design and independent innovation, we attach great importance to the preparatory process. The experimental preparation assessment is divided into three sections, one is the online assessment under the class, the second is the preview report, and the third is the classroom teacher's spot check.

a) Online assessment under the class:

Students need to preview the experiment before entering the lab. There are some preview questions for each experiment in our textbook, and the students should understand these preview questions. There is a preparatory laboratory with one or two sets of experimental instruments for each experiment in our college physics experimental center, which are open all day for students to preview the instrument. After the preview, students can take the preview test on the Internet. If the test is unqualified, students can't make an appointment for the lab class online.

b) Preview report:

After students participate in the preview test on the Internet, they also need to write a preview report. If there is no preview report, they cannot go to the lab.

c) Classroom spot check:

Before experiment, teachers check the preview situation of some students. If the students' check is unqualified, they can't take the experimental class, and need to preview experiment and participate in the preview test online again.

After students have undergone three preview assessments, they have basically understood the various contents of the experimental project. Some students maybe put forward their own problems, their own ideas and their own goals after the preparation of such a preview. It can be said that the more students prepare and the more work they have, the more interested they are in the experiment.

2) Experimental operation and literacy:

Students who complete the experiment must be checked whether the data is qualified by the teacher. If the data is unqualified, the experiment must be redone; if the data is qualified, the teacher will give the experimental operation and literacy score according to the student performance. If students have innovations in experimental operations and measurements, or do targeted research and discussion about the phenomena and problems that appear in the experiment, or actively complete the selection of experimental content, they will be given extra points. We encourage students to think positively and be innovative in the expe- 
riment.

3) Experimental report:

Teachers give the score of the experimental report according to the students' data process, the experimental results, and the discussion of the experimental questions. In the experimental report, if the students have a thorough analysis of the experimental problems, or have their own insights, or have their own unique experience, or have a targeted analysis and discussion of the special phenomena and problems that appear in the experiment, they will be given extra points, which is designed to develop students' ability to analyze and solve problems.

\subsection{The Score of Extracurricular Expansion Experiment}

The score of extracurricular expansion experiments is 10 points, and divided into three parts: topic-selecting report (20\%), mid-term examinations (30\%), and concluding report (50\%).

The students are required to choose one extracurricular expansion experiment in each semester. After four weeks of the beginning of experimental class, students can investigate the related extracurricular expansion experiment by themselves based on the four-week classroom discussion. They need to self-prepare the topic, self-design the experimental plan, and write a topic-selecting report. If the topic-selecting report is unqualified, they need to select a topic again and rewrite the topic-selecting report. The next work can be carried out until qualified.

In the tenth week of the experimental class, students are required to submit a mid-term progress report, including the progress of the experiment, the problems that occurred in the experiment, the difficulties that they encountered, the gains and the thoughts in experiments, and the next plan and so on. The instructor gives the mid-term score according to the students' usual experiments and the mid-term progress report. Students who fail to pass the mid-term examination may be dealt with in the following three ways according to the actual situation: 1) after improvement, the extracurricular expansion experiment can be continued; 2) after warning and observation of their improvement, decide whether to continue or stop the extracurricular expansion experiment; 3) stop the extracurricular expansion experiment directly.

At the end of the semester, students are required to submit a concluding report and experimental results. The concluding report includes: background of the topic, experimental content and methods, experimental results, experimental analysis and discussion, innovation points, references. Other experimental results include: design, software, models, devices, papers, patents, etc. The instructor gives the score based on the students' usual experimental performance, experimental results and concluding report.

\section{Evaluation Criteria for Individual Experimental Project}

\subsection{Evaluation Criteria for Individual Experiment in Class}

The formulation of classroom experiment evaluation criteria should be changed 
from the assessment of "study performance" to the evaluation of "learning effectiveness", and guide students to shift from "examination results" to "learning process". The score of college physics experiments is not based on the difference between the actual experimental results and the expected ones, but based on the comprehensive performance of the students' experimental knowledge, experimental ability, experimental attitude, etc.. We must encourage innovation and not just be satisfied with completing the experiment. The specific evaluation criteria are shown in Table 1. Each evaluation item in the table has different evaluation criteria, and each standard requires a certain weight on a 10-point scale.

\subsection{Evaluation Criteria for Extracurricular Expansion Experiments}

The extracurricular expansion experiment aims to improve students' ability and quality in self-learning, problem solving, project management, comprehensive innovation, etc., in which students can experience the process of project learning and management, stimulate their interest in scientific and technological innovation and scientific research, and improve their innovation ability. The experiment follows the principle of "interest driven, independent experiment, and emphasis on process". The whole process reflects the characteristics of independent planning, independent learning, independent design and independent realization. Therefore, the evaluation system should be process-oriented, the implementation process and implementation results can be all objectively evaluated. This evaluation system can guide students to pay attention to the experimental process, initiative practice, and continuous innovation. The specific evaluation criteria are shown in Table 2. Each evaluation item in the table has different evaluation criteria, and each standard requires a certain weight on a 10-point scale.

\section{Conclusion}

The current phased comprehensive evaluation method of our physics experiment course has changed from the previous "study achievement" evaluation method to the "learning effect" valuation method. The evaluation system is process-oriented, in which the implementation process and implementation results can be all objectively evaluated, and students can be guided to pay attention to the experimental process, take the initiative to practice, and constantly innovate. This evaluation system plays a guiding role in the students' transition from "examination results" to "learning process". This evaluation method has fully mobilized the enthusiasm and initiative of students, which has greatly changed the phenomenon that students do not pay attention to the college physics experiment class, are not active, and only experiment with taking credits. This kind of evaluation and assessment method is also conducive to fully exploring the potential of students, cultivating their proactive exploration spirit, scientific thinking ability, innovation ability and consciousness, and cultivating their awareness and ability of independent cooperation, inquiry learning and lifelong 
Table 1. Evaluation criteria for classroom experiment projects.

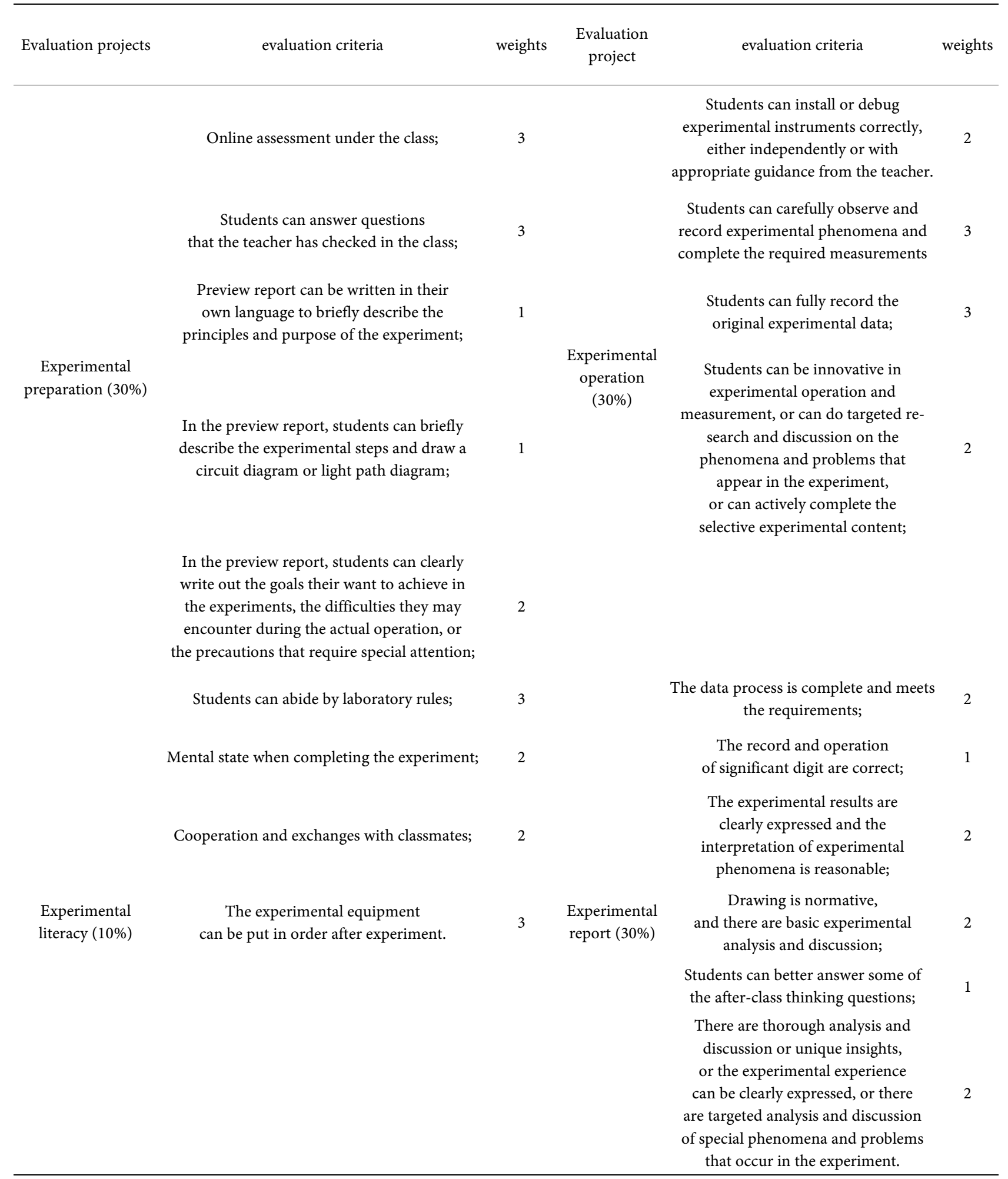

learning, in which students can realize self-awareness, self-regulation, self-improvement, self-development, the individualization of learning and the humanization of education. 
Table 2. Evaluation criteria for extracurricular expansion experiments.

\begin{tabular}{|c|c|c|c|c|c|}
\hline $\begin{array}{l}\text { Evaluation } \\
\text { projects }\end{array}$ & evaluation criteria & weights & $\begin{array}{c}\text { Evaluation } \\
\text { project }\end{array}$ & evaluation criteria & weights \\
\hline \multirow{4}{*}{$\begin{array}{l}\text { topic-selecting } \\
\text { report }(20 \%)\end{array}$} & Preliminary investigation and preparation; & 3 & & $\begin{array}{l}\text { The situation of the experimental } \\
\text { work records, whether the experimental } \\
\text { process is recorded in detail, } \\
\text { accurately and in real time; }\end{array}$ & 2 \\
\hline & $\begin{array}{l}\text { The orderliness of the experimental } \\
\text { scheme, the rationality of the experimental } \\
\text { design, the feasibility of the method, etc.; }\end{array}$ & 2 & & $\begin{array}{l}\text { The ability to collect documentation, } \\
\text { process information, } \\
\text { and acquire new knowledge; }\end{array}$ & 1 \\
\hline & $\begin{array}{l}\text { The scientific nature of the topic, the novelty } \\
\text { of the content, and the value of research; }\end{array}$ & 2 & & $\begin{array}{l}\text { Students can correctly design the } \\
\text { experimental plan, complete the experi- } \\
\text { mental work independently, and } \\
\text { the experimental results are correct; }\end{array}$ & 1 \\
\hline & $\begin{array}{c}\text { Whether the research objectives are clear, } \\
\text { whether there are visualized } \\
\text { experimental processes and data, } \\
\text { or quantifiable comparison results; }\end{array}$ & 3 & Concluding & $\begin{array}{l}\text { The student's experimental workload is } \\
\text { full and difficult, students work hard, } \\
\text { their work style is solid and rigorous; }\end{array}$ & 2 \\
\hline \multirow{4}{*}{$\begin{array}{l}\text { Mid-term } \\
\text { examinations } \\
\quad(30 \%)\end{array}$} & $\begin{array}{l}\text { The situation of the experimental work } \\
\text { records, including whether the } \\
\text { experimental process is recorded } \\
\text { in detail, accurately and in real time; }\end{array}$ & 3 & Report (50\%) & $\begin{array}{l}\text { There is a sense of innovation } \\
\text { in the experiment, or improvement } \\
\text { and breakthrough in the work } \\
\text { of the predecessors, or } \\
\text { unique insights in the experiment; }\end{array}$ & 2 \\
\hline & $\begin{array}{l}\text { The progress of the project, } \\
\text { mainly preliminary } \\
\text { experimental conditions; }\end{array}$ & 3 & & $\begin{array}{l}\text { Students can apply the knowledge and } \\
\text { skills learned to discover, analyze and } \\
\text { solve practical problems, correctly } \\
\text { process experimental data, theoretically } \\
\text { analyze the experiment, and } \\
\text { draw valuable conclusions. }\end{array}$ & 2 \\
\hline & The ability to solve difficulties; & 2 & & & \\
\hline & $\begin{array}{l}\text { Whether the final overall plan is } \\
\text { feasible and reasonable, and } \\
\text { whether the next work plan is detailed. }\end{array}$ & 2 & & & \\
\hline
\end{tabular}

\section{Fund Project}

Teaching Reform Research Project of Undergraduate Universities in Shandong Province (B2016M020); Harbin Institute of Technology at Weihai Teaching Research Project (ITGA 10002016).

\section{Conflicts of Interest}

The authors declare no conflicts of interest regarding the publication of this paper.

\section{References}

[1] Teaching Steering Committee of Physics and Astronomy in Colleges and Universities of the Ministry of Education, Subcommittee on Teaching Guidance of Basic Physics Courses (2011) Basic Requirements for the Teaching of College Physics Experiments in University of Science and Technology (2010 Edition). Higher Educa- 
tion Press, Beijing.

[2] Cui, X.R., Cao, A.Y., Li, J., et al. (2016) The Application of Research-Based Teaching Model in the Reform of Experimental Teaching Method. Experimental Technology and Management, 33, 176-178.

[3] Ma, S.Y., Wang, H., Wu, F.P., et al. (2015) The Practice of Improving the Ability of Autonomous Learning in the Experiment of Autonomy Interest. Experimental Technology and Management, 32, 194-196.

[4] Ding, X.M., Zhang, X.J., Wang, P., et al. (2015) The Application of flipping classroom Teaching Model in College Experimental Teaching. Laboratory Research and Exploration, 34, 207-212.

[5] Geng, H.X. and Jiang, X.L. (2015) Exploration and Practice of Comprehensive Experimental Teaching Reform. Laboratory Research and Exploration, 34, 147-149.

[6] Song, J.F., Guo, X.F., Wang, S.Z., et al. (2015) Application of Micro-Course in College Physics Experiment Teaching. Physics Experiment, 35, 12-17.

[7] Wei, Y.L. and Yang, L. (2015) Exploration of the layered Teaching Model of College Physics experiment. College Physics Experiment, 28, 126-128.

[8] Wan, W. (2015) Discussion on the Cultivation of Creative Ability in the Hierarchical Teaching of Physics experiment. College Physics Experiment, 28, 128-130.

[9] Duan, X.S., Zhang, X., Zhang, Z.D. (2015) The Construction and Practice of College Physics Experiment Teaching System for Students' Autonomous Learning. Experimental Technology and Management, 32, 187-190.

[10] Zhang, Y.H. (2013) Construction of Physical Experiment Teaching System with Outstanding Ability of Practical Innovation. College Physics, No. 12, 43-45.

[11] Zhu, H., Wang, W., Suo, Y.J. (2011) Exploration and Practice of Examination Methods of College Physics Experiment Course. Experimental Science and Technology, 9, 108-111.

[12] Li, L., Li, Y.C. and Zhong, H.J. (2010) The Reform and Practice of Different Examination Methods in Physics Experiment Class-The Positive Effect of Operation Test Is Most Obvious. College Physics, 29, 43-46.

[13] Li, M., Hong, W.N., Qian, L.C., et al. (2011) Practice on the Comprehensive Examination Method of College Physics Experiment. University Physics Experiment, 24, 104-105.

[14] Yuan, A.J. and Ding, X.H. (2009) Evaluation of the Examination Methods of College Physics Experiments. College Physics Experiment, 22, 117-119.

[15] Wu, X.Q., Yao, X.L., Chen, J.B., et al. (2015) Study on the Examination Method of the Stage of College Physics Experiment. Physics and Engineering, 25, 66-70.

[16] Liu, Z.X. and Yang, D. (2012) A Probe into the Reform of the Examination Mode of College Physics Experiment Course. Journal of Higher Education Research, 35, 105-106. 